\title{
Developing Electronic Health Record (EHR) Strategies Related to Health Center Patients' Social Determinants of Health
}

\author{
Rachel Gold, PhD, MPH, Erika Cottrell, PhD, MPP, Arwen Bunce, MA, \\ Mary Middendorf, BS, Celine Hollombe, MPH, Stuart Cowburn, MPH, \\ Peter Mahr, MD, and Gerardo Melgar, MD
}

Background: "Social determinants of heath" (SDHs) are nonclinical factors that profoundly affect health. Helping community health centers (CHCs) document patients' SDH data in electronic health records (EHRs) could yield substantial health benefits, but little has been reported about CHCs' development of EHR-based tools for SDH data collection and presentation.

Methods: We worked with 27 diverse CHC stakeholders to develop strategies for optimizing SDH data collection and presentation in their EHR, and approaches for integrating SDH data collection and the use of those data (eg, through referrals to community resources) into CHC workflows.

Results: We iteratively developed a set of EHR-based SDH data collection, summary, and referral tools for CHCs. We describe considerations that arose while developing the tools and present some preliminary lessons learned.

Conclusion: Standardizing SDH data collection and presentation in EHRs could lead to improved patient and population health outcomes in CHCs and other care settings. We know of no previous reports of processes used to develop similar tools. This article provides an example of 1 such process. Lessons from our process may be useful to health care organizations interested in using EHRs to collect and act on SDH data. Research is needed to empirically test the generalizability of these lessons. (J Am Board Fam Med 2017;30:428-447.)

Keywords: Community Health Centers, Data Collection, Electronic Health Records, Primary Health Care, Referral and Consultation, Social Determinants of Health

Numerous health outcomes are influenced by the social and physical characteristics of patients' lives. These "social determinants of heath" (SDHs) can affect health via diverse mechanisms (eg, chronic stress, hampering patients' ability to follow care recommendations). ${ }^{1}$ This impact is so great that

This article was externally peer reviewed.

Submitted 14 February 2017; revised 14 February 2017; accepted 18 February 2017.

From the Center for Health Research, Kaiser Permanente Northwest, Portland, OR (RG, AB, CH); OCHIN, Inc., Portland (RG, EC, MM, SC); the Multnomah County Health Department, Portland (PM); and the Cowlitz Family Health Center, Longview, WA (GM).

Funding: This publication was supported by the National Institute of Diabetes and Digestive and Kidney Diseases (grant R18DK105463).

Conflict of interest: none declared.

Corresponding author: Rachel Gold, $\mathrm{PhD}, \mathrm{MPH}$, Kaiser Permanente Center for Health Research, 3800 N. Interstate Ave, Portland, OR 97227 (E-mail: rachel.gold@kpchr.org). addressing SDHs may improve health as much as addressing patients' medical needs. ${ }^{2-21}$

The Institute of Medicine (IOM) recommended that 10 patient-reported SDH domains (and 1 neighborhood/community-level domain) be documented in electronic health records $(\mathrm{EHRs})^{22,23}$ (Table 1). These domains were selected based on evidence of their health impacts; their potential clinical usefulness and ability to put into action; and the availability of valid measures. Some of these domains (eg, race/ethnicity) are already regularly collected by federally funded clinics; others (eg, social isolation, financial resource strain) are not. The Centers for Medicare \& Medicaid Services intended that the IOM's report inform stage 3 meaningful use EHR incentive program requirements. Related to this, the Medicare Access \& CHIP Reauthorization Act of 2015 and Centers for 
Table 1. Institute of Medicine Phase 2 Report: Summary of Candidate Domains for Inclusion in All Electronic Health Records

Race/ethnicity*

Education

Financial resource strain

Stress

Depression*

Physical activity

Nicotine use/exposure*

Alcohol use*

Social connections/social isolation

Exposure to violence: intimate partner violence

Neighborhood characteristics (eg, median income within census tract)

*Already routinely captured in electronic health records.

Medicare \& Medicaid Services' 2016 Quality Strategy both emphasize care providers identifying and intervening in SDH-related needs. In addition, the Health Resources and Services Administration and the Office of the National Coordinator for Health Information Technology have both indicated that SDH data collection should continue to expand as part of federally qualified health center reporting, and may become required for EHR certification. ${ }^{24-29}$

Systematically documenting patients' SDH data in EHRs could help care teams incorporate this information into patient care, for example, by facilitating referrals to community resources to address identified needs. This could be especially useful in "safety net" community health centers (CHCs), whose patients have higher health risks than the general US population..$^{230-39}$ Many CHCs already try to address patients' SDHs, but their approaches to doing so have historically been manual and ad hoc. ${ }^{40-44}$

EHRs present an opportunity to standardize the collection, presentation, and integration of SDH data in CHCs' clinical records. ${ }^{45}$ Toward that end, a national coalition of CHC-serving organizations created the "Protocol for Responding to and Assessing Patient Assets, Risks, and Experiences" (PRAPARE), which included a preliminary SDH data collection tool informed by the IOM's phase 1 report. ${ }^{45}$ PRAPARE includes most of the IOMrecommended domains and a few additional questions specific to $\mathrm{CHC}$ populations. Building on PRAPARE and the IOM recommendations, our study team asked CHC stakeholders about their opinions on how to optimize SDH data collection, documentation, and presentation in CHCs' EHRs, and on how they would like to use EHR tools to act on identified SDH-related needs, for example, by making referrals to community resources. This article describes our process and its results. We know of no previously published reports of processes used to develop EHR-based SDH data collection, summary, and referral tools, and therefore we present this article as an example that may inform others.

\section{Methods}

This work was conducted at OCHIN, a nonprofit community-based organization that centrally hosts and manages an Epic@ EHR for $>440$ primary care CHCs in 19 states; it is the nation's largest CHC network on a single EHR system. Socioeconomic risks of patients in OCHIN member CHCs are clear from SDH data that are already collected: $23 \%$ are uninsured and 58\% are publicly insured, $25 \%$ are nonwhite, $33 \%$ are of Hispanic ethnicity, $28 \%$ are primarily non-English speakers, and $91 \%$ are from households living $<200 \%$ below the federal poverty level (among patients with available data).

The processes described here constituted the first phase of a pilot study designed to develop EHR-based tools that CHCs could use to systematically identify and act on their patients' SDHrelated needs. We call these the "SDH data tools."

With the goal of creating SDH-related workflows that parallel clinical referral processes, we began with the assumption that addressing patients' SDH needs require 5 key steps: (1) collecting SDH data; (2) reviewing patients' SDH-related needs; (3) identifying referral options to address those needs; (4) ordering referrals to appropriate services; and (5) tracking outcomes of past referrals. This assumption was based on team members' knowledge of the CHC workflows used to refer patients to specialty medical care.

We also considered the following factors:

- CHCs are federally required to collect certain $\mathrm{SDH}$ measures from the IOM list, including race/ethnicity, tobacco/alcohol use, and depression. Our SDH data tools had to incorporate these data, without requiring duplicate data entry. 
Table 2. Options Considered for Addressing Each of the Five Steps Involved in Using Social Determinants of Health Data in Community Health Centers

\begin{tabular}{|c|c|c|}
\hline Step & Options & Description \\
\hline \multirow[t]{3}{*}{ 1. Collecting SDH data } & Flowsheet & $\begin{array}{l}\text { Groups of related data can be collected in a given EHR "flowsheet." Flowsheets } \\
\text { are commonly used for collecting screening data, such as depression } \\
\text { screenings, so users may also be comfortable using them for SDH } \\
\text { documentation. }\end{array}$ \\
\hline & Patient portal & $\begin{array}{l}\text { In the EHR patient portal, patients sign up for an account. This lets them } \\
\text { access selected data from their medical record and E-mail their care teams. } \\
\text { Questionnaires and surveys can also be sent to be completed and returned by } \\
\text { patients through the portal. }\end{array}$ \\
\hline & Paper version & $\begin{array}{l}\text { Patient-reported data are often collected on hard-copy printouts. These data } \\
\text { must subsequently be entered into the EHR by a care team member. }\end{array}$ \\
\hline 2: Reviewing SDH needs & Reports & $\begin{array}{l}\text { Summaries of selected patient data can be created in the EHR in the Synopsis } \\
\text { function, or in Patient-Level Reports. }\end{array}$ \\
\hline \multirow[t]{2}{*}{ 5: Tracking past referrals } & Rosters & $\begin{array}{l}\text { The EHR's panel management tool lets users sort patient panel data for myriad } \\
\text { purposes. Rosters and registries can be built so that updated data sets are } \\
\text { easily reproduced; experienced users can create customized searches. Rosters } \\
\text { can be used to identify patients with specific diseases or risks for use in tasks } \\
\text { such as targeted outreach or for identifying the needs of scheduled patients } \\
\text { (ie, chart "scrubbing"). They can be used to track referrals made over a given } \\
\text { period in order to support follow-up by the care team. }\end{array}$ \\
\hline & Alerts & $\begin{array}{l}\text { Two EHR-based alert/reminder functions are available. Best Practice Advisories } \\
\text { identify needed care steps, drug allergies or other safety warnings, and other } \\
\text { point-of-care needs. Health Maintenance alerts notify team members when a } \\
\text { patient is due for preventive care; at OCHIN, these include recommendations } \\
\text { with a US Preventive Services Task Force A/B rating. }{ }^{46}\end{array}$ \\
\hline $\begin{array}{l}\text { 3: Identifying referral } \\
\text { options }\end{array}$ & Preference lists & $\begin{array}{l}\text { Preset lists of specified kinds of orders can be built to expedite ordering } \\
\text { procedures, medications, and referrals. They are maintained by a clinic staff } \\
\text { member. }\end{array}$ \\
\hline \multirow[t]{4}{*}{ 4: Ordering referrals } & Look-up tables & These tables could be created with an initial set of local resources. \\
\hline & $\begin{array}{l}\text { Linkages to } \\
\text { websites }\end{array}$ & $\begin{array}{l}\text { These linked websites might list community social services (eg, United Way } \\
2-1-1 \text {, Purple Binder, Health Leads), in general or for a specific SDH need, } \\
\text { within the patient's zip code. }\end{array}$ \\
\hline & $\begin{array}{l}\text { Lists of search } \\
\text { terms }\end{array}$ & $\begin{array}{l}\text { Lists could be created to enable effective Internet searching for local resources } \\
\text { (eg Google) in a wiki-style document with vetted search terms and } \\
\text { suggestions for how to use Google Maps to locate services. }\end{array}$ \\
\hline & $\begin{array}{l}\text { A wiki-style } \\
\text { document }\end{array}$ & $\begin{array}{l}\text { Lists of local resources familiar to CHC staff could be added to the EHR and } \\
\text { updated as needed. }\end{array}$ \\
\hline
\end{tabular}

CHC, community health center; EHR, electronic health record; SDH, social determinant of health.

- CHCs have varying staffing structures, resources, and workflows. To accommodate this, SDH data tools should be accessible to various team members (eg, front desk, medical assistants, community health workers, behavioral health staff).

- SDH tools should use existing EHR-based functionalities to facilitate their adoption. Table 2 describes the options we initially considered to address each of these 5 steps.

- Many CHCs already identify or address SDH needs using ad hoc methods. Some may already have mechanisms for tracking local resources, such as a 3-ring binder or files on a shared drive; some use online resources (eg, United Way 2-1-1, local department of human services). We sought to incorporate existing resources into our SDH referral tools.
We recruited 3 OCHIN CHCs in Oregon and Washington as pilot sites and project partners. We also engaged OCHIN's Clinical Operations Review Committee (CORC) - a group of CHC clinicians who collectively review proposed changes to their shared EHR - in all process steps. We conferred with leaders from PRAPARE, Kaiser Permanente (KP), Epic, and other national SDH experts (see the Acknowledgments). These stakeholders were asked to discuss 3 overarching questions.

\section{Which SDH Domains Should be Included?}

The CORC reviewed the IOM-recommended SDH domains and the wording for each domain, additional questions or alternate wording from PRAPARE and KP's SDH screening tools, and other domains currently collected in OCHIN's 
EHR that were not in the IOM/PRAPARE recommendations. Based on these options, they chose which patient-reported SDH measures to include and the specific wording for each included domain. Geocoded domains were not considered, as the CORC felt they were not readily actionable. The pilot CHCs were present at most of the SDHrelated CORC meetings.

\section{How Do Care Teams Want to Collect, Review, and Act on Data on Patients' SDH Needs within the EHR?} We asked CORC members whether and how their clinics monitor patients' SDHs and what the SDHrelated EHR tools should include. We presented options for how the SDH data could be collected and summarized using existing EHR structures, and we considered how existing tools aligned with the 5 key steps described above. We then mocked up a set of SDH data EHR tools and proposed workflows for using them. We presented the mock-ups and draft training materials to the CORC over multiple meetings, and to each of the pilot CHCs at staff meetings. We asked diverse CHC staff for critical feedback on the draft tools, suggestions for and potential barriers to collecting and acting on SDH data using the tools, and how best to train CHC staff in their use. Our team's Epic programmer attended these meetings to provide real-time input about the technical feasibility of any suggestions. The SDH data tools were revised based on the feedback received, and the pilot CHCs' various workflows and staff structures were considered. The revised tools were presented to the CORC (in person) and the study sites (via webinar) to verify that the revisions addressed requested changes.

This review and refinement process aligns with best practices for technology development, ${ }^{47}$ for example, user participation and prototyping. ${ }^{48-55}$ Evidence shows that for technology to be used effectively and as intended, end users must find it easy to use and must perceive that the technology will improve efficiency. ${ }^{56-58}$ Therefore, we sought input from end users in order to increase the probability that the tools would be used. ${ }^{47}$ The EHR tools were then built in OCHIN's testing environment, an off-line, internal "copy" of the EHR, and tested by an OCHIN quality assurance analyst.

\section{How Can Care Teams Ensure That Patients Receive Up-to-Date Referrals?}

The CHCs hoped to avoid referring patients to local resources that were not currently accepting new clients (service agencies sometimes close enrollment because of demand) or that had limitations about who could be assisted (eg, some services are not open to persons with past felonies). We discussed the options and approaches for identifying resources described above. We also conferred with colleagues at KP who were considering similar choices, and we spoke with representatives from organizations that create databases of community resource information (eg, United Way 2-1-1, Health Leads, and Purple Binder) to understand those options. The 3 pilot clinics then identified 3 to 5 prioritized $\mathrm{SDH}$ domains for which they wanted a list of community resources; based on these preferences, we provided lists of local resources for housing, food, transportation, social isolation, and intimate partner violence.

\section{Participants}

Participants from our study clinics consisted of primary care providers $(\mathrm{n}=3)$, medical assistants $(\mathrm{n}=5)$, clinic managers $(\mathrm{n}=3)$, community health workers $(n=4)$, behavioral health staff $(n=2)$, nurses $(\mathrm{n}=5)$, referral specialists $(\mathrm{n}=3)$, EHR specialists $(n=3)$, and medical directors $(n=2)$.

\section{Timeline}

The development process took 10 months. Five 1-hour meetings with the CORC were held over the course of 6 months in order to reach consensus on which $\mathrm{SDH}$ domains to include and how the tool would function. The pilot sites were then given 6 weeks to test the tools for functional errors.

\section{Results}

\section{Which SDH Measures?}

Our stakeholders asked that the SDH tools include all the patient-reported IOM-recommended domains, made minor adaptations to the wording on some of these domains, and added a few questions (Tables 1 and 3). For example, the IOM's single question on financial resource strain asks, "How hard is it for you to pay for the very basics like food, housing, heating, medical care, and medications?" (not hard at all, somewhat hard, very hard). Because CHCs treat low-income patients, many of whom 


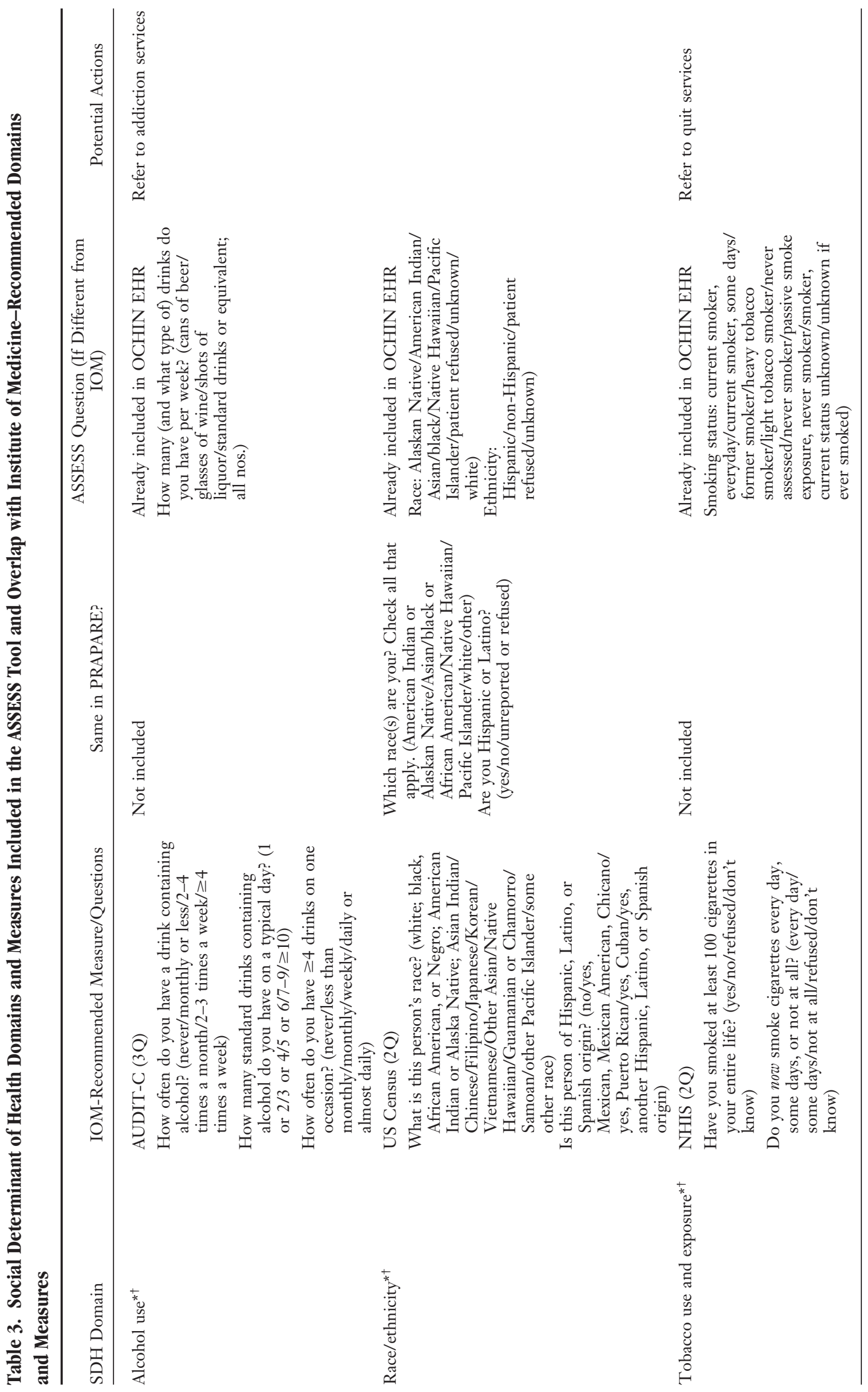




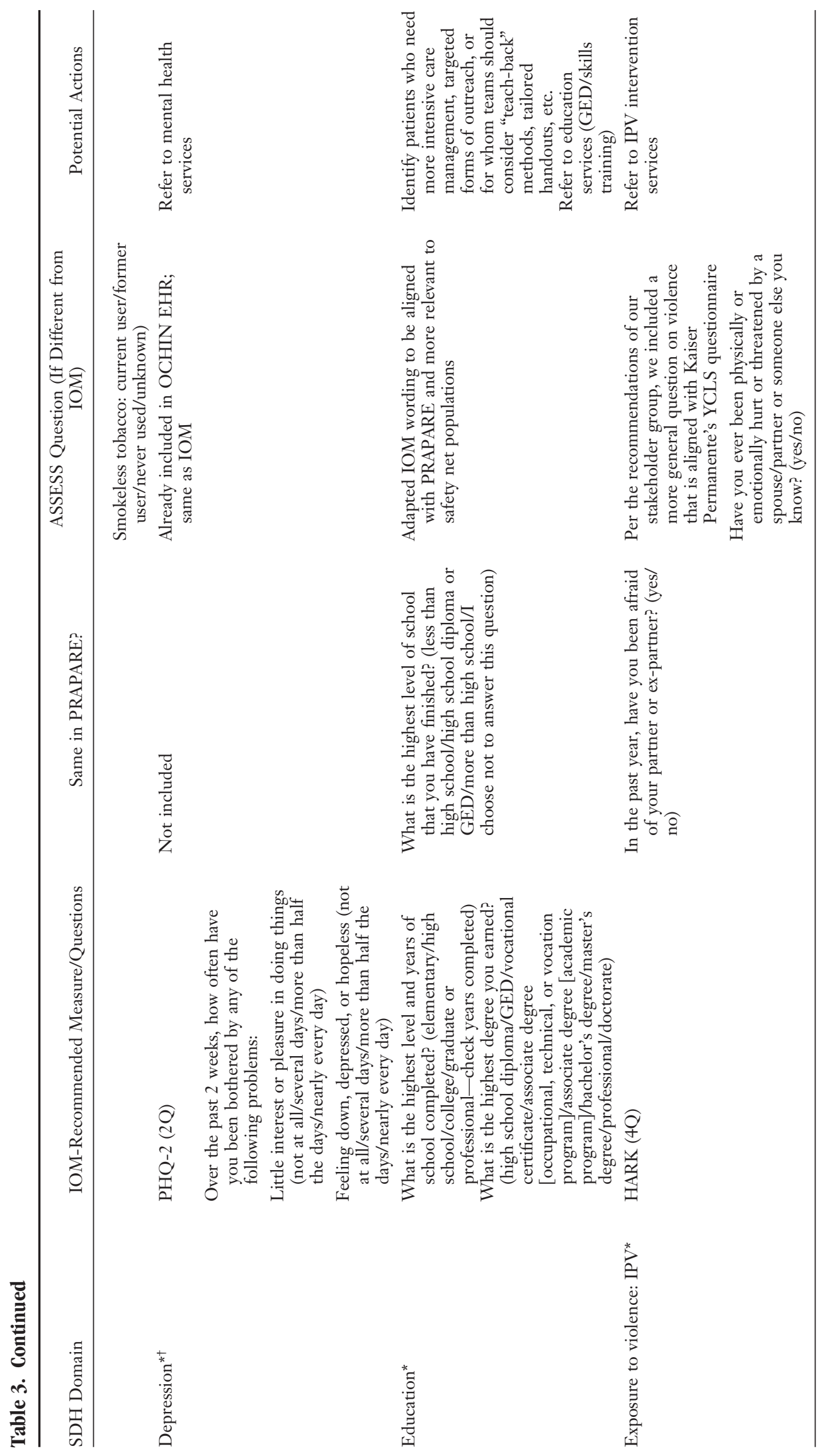




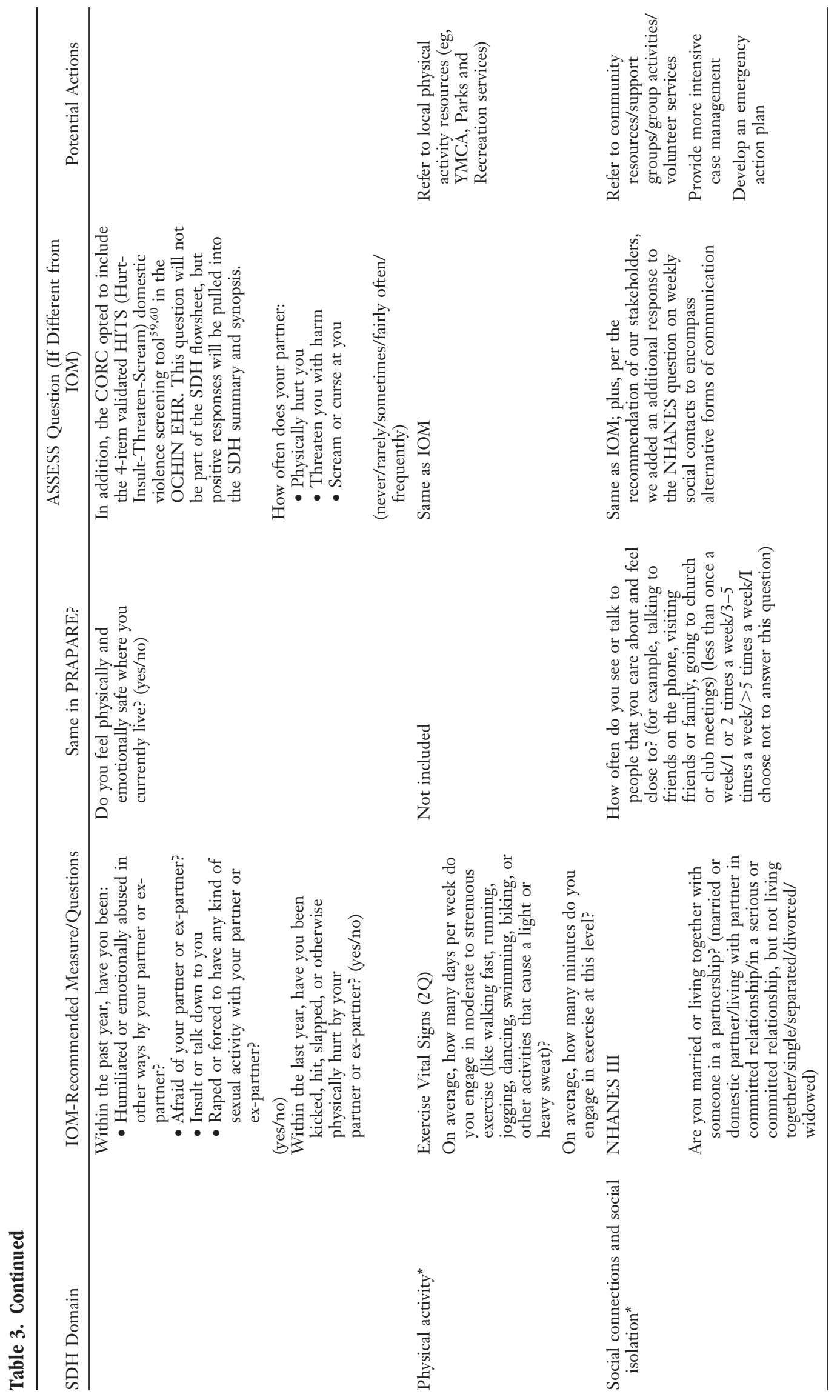




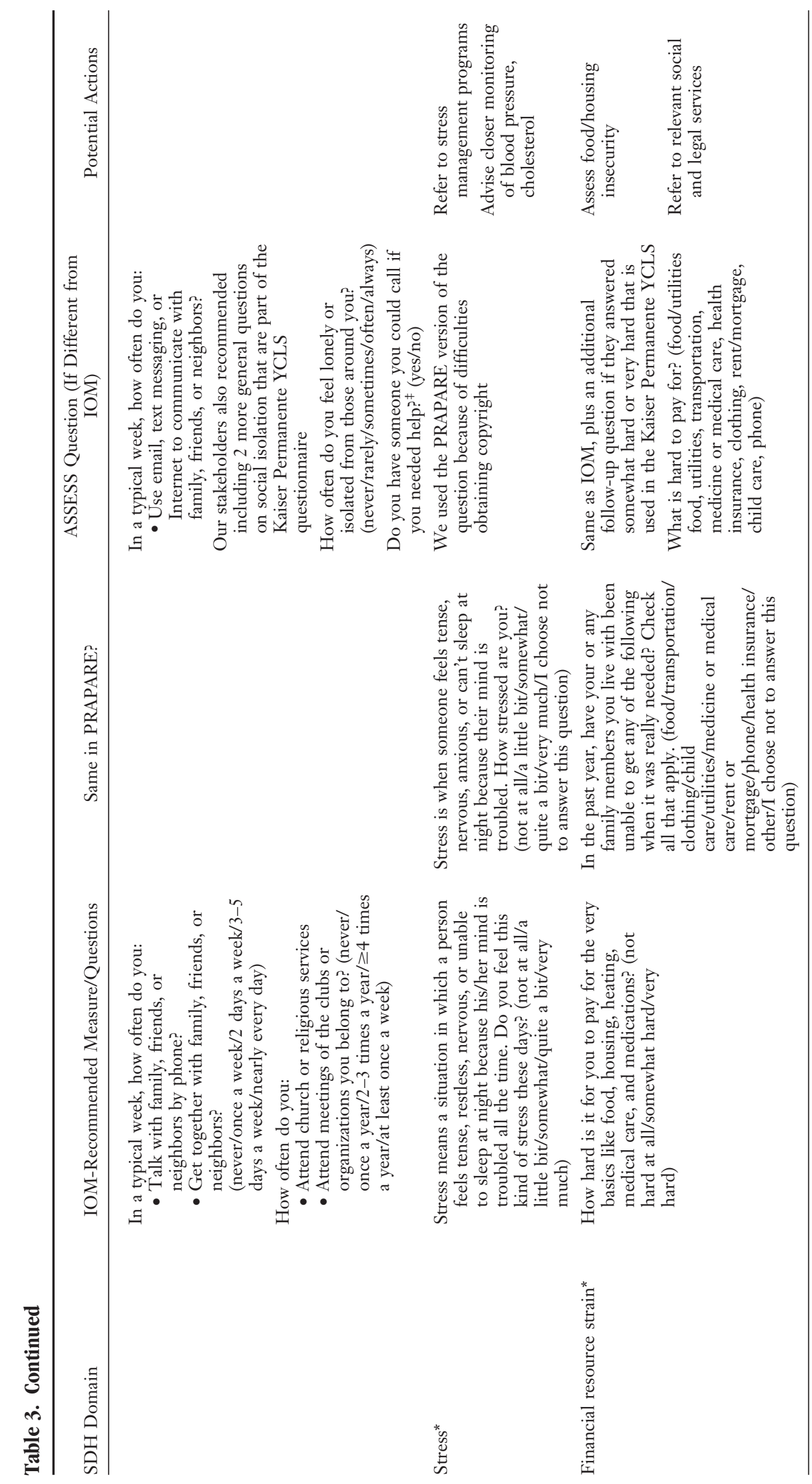




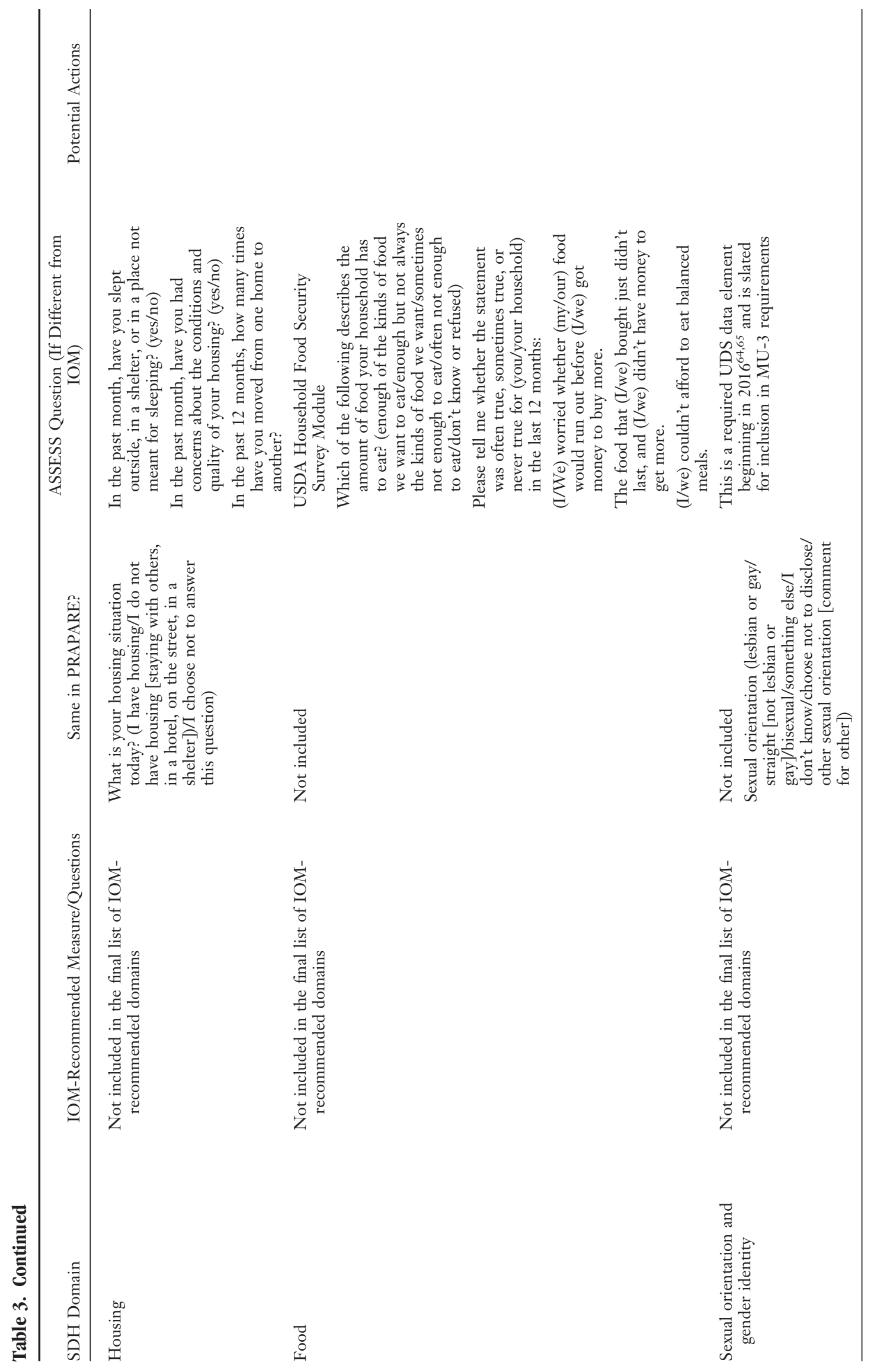




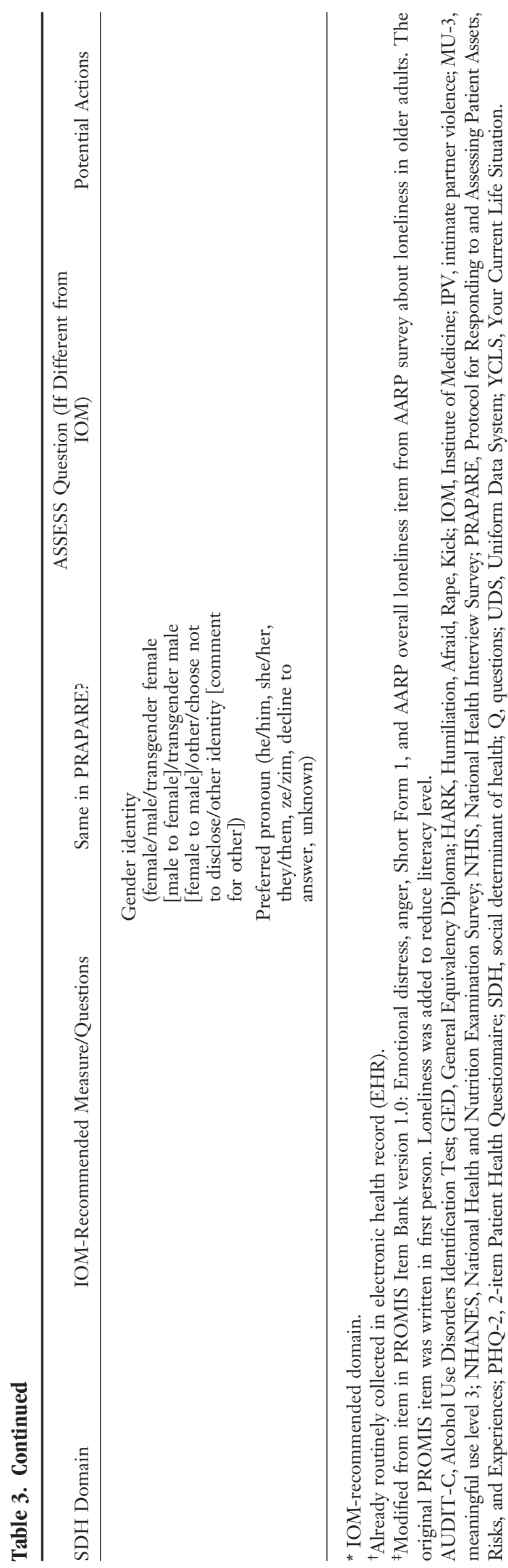

are likely to screen positive for financial hardship, the CHC stakeholders wanted to augment this broad question with more granular questions about specific areas of strain (eg, food, utilities, transportation). The hope was that this granularity would identify the specific areas in which assistance was needed. The stakeholders also preferred to not use the IOM-recommended screening tool for intimate partner violence; they considered its questions too sensitive for general SDH screening. They opted for a broader question about exposure to violence that was taken from KP's SDH questionnaire. They also opted to add 2 questions on social isolation from KP's questionnaire (eg, "How often do you feel lonely or isolated from those around you?"; "Do you have someone you could call if you needed help?"), along with the IOM-recommended questions on social isolation. They also added a question on preferred learning style (eg, reading, listening, viewing pictures).

\section{Collecting SDH Data}

Stakeholder feedback, and our understanding that $\mathrm{CHC}$ workflows vary, indicated the need to enable SDH data collection by different care team members. Because EHR security measures limit which staff can access aspects of the EHR (for example, front desk staff often cannot access the problem list), we created several options for SDH data entry:

- SDH "documentation flowsheets" were accessible to front desk staff at check-in, rooming staff, or community health workers (Figure 1).

- Article versions of the SDH questions, in English or Spanish, that can be printed out and handed to the patient to complete at check-in or rooming, were provided on OCHIN's member wiki site. These data would have to be hand-entered by CHC staff into 1 of the EHR flowsheets described above.

- A questionnaire on the patient portal allowed patients who had an online portal account to be emailed and asked to enter the data online before a visit. The EHR's panel management tool can identify patients with pending visits and enable bulk secure messages to these patients. Within the portal, patients can choose navigational instructions in Spanish, but the screening questions are available only in English. 
Figure 1. Social determinants of health flowsheet in EPIC.

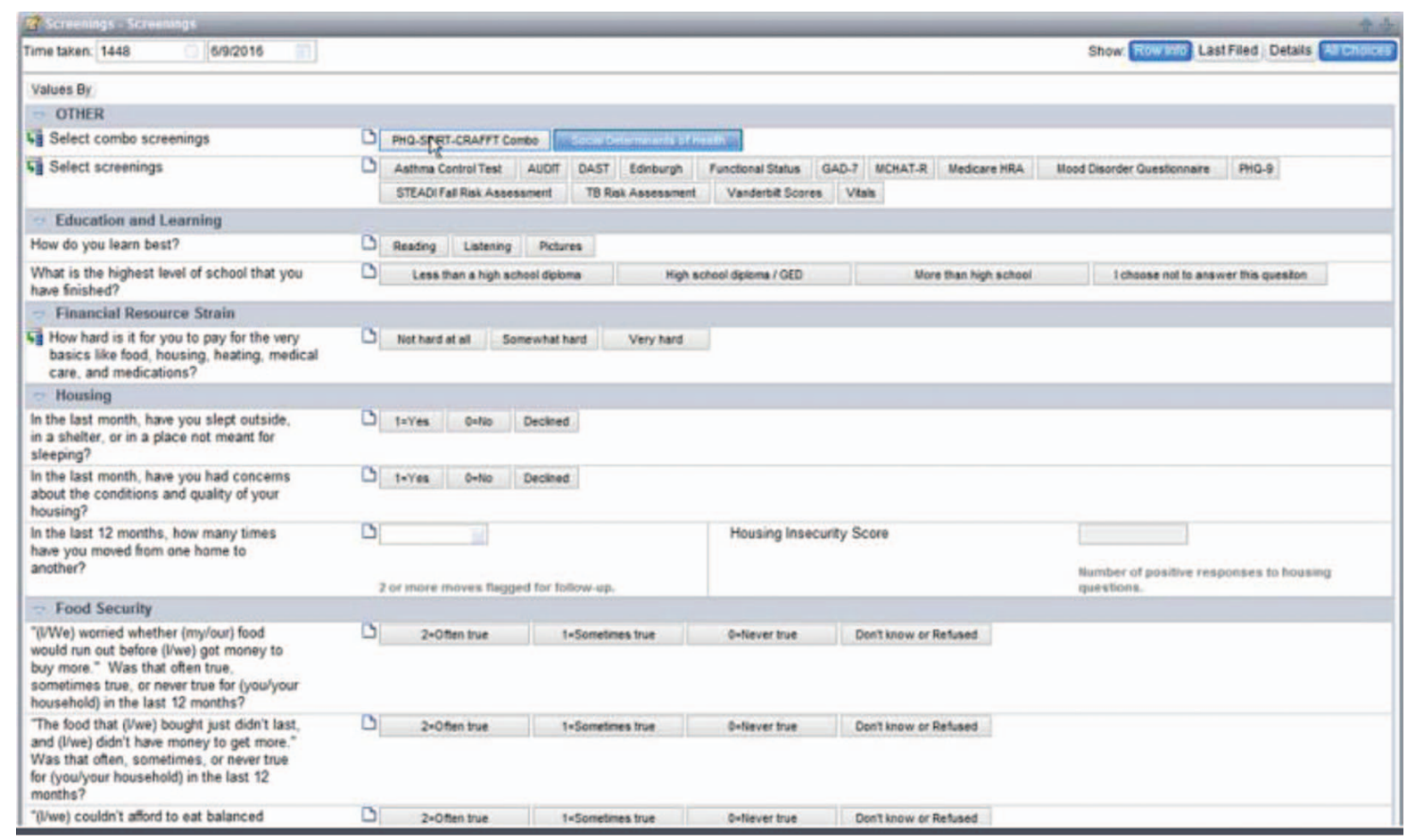

We discussed various considerations during this process:

- Making an electronic tablet available in the clinics' waiting rooms or examination rooms, on which patients could complete their SDH screening. Two of the pilot CHCs decided it would be too complex to manage, for example, identifying who would be the tablet's "keeper," where it would be stored, and how to identify which patients should use it.

- Creating a setting on the computer in the examination room where patients could sign up for a patient portal account then complete the SDH data through the portal immediately. In the end, this proved unfeasible because the patient must be sent the questionnaire after they sign up for the portal, necessitating an impractical multistep workflow.

- Clinicians did not want to collect SDH data themselves, preferring to transfer that responsibility to another team member. Two of the pilot sites opted to use the Article forms for data collection, then have a staff person enter the data into the EHR. This approach creates potential workflow barriers to use of the SDH tools, be- cause until the responses are manually transferred into the chart, the data will not be available to care team members to act on during the encounter.

- All options for reminding the team to conduct SDH screening were considered inadequate. Clinics said that best practice advisories (also known as alerts) are largely ignored. They preferred health maintenance advisories (HMAs), which are closely integrated into clinic workflows. However, HMAs must be standardized across all clinics using a shared EHR; because a universal HMA was not possible, HMAs were not a feasible option.

- Similar to other screening questionnaires administered in clinical settings, clinics asked that the patient-facing data collection form not include a "refuse to answer" option. The staff-entered methods did include this option.

\section{Reviewing Data on Patients' SDH Needs}

SDH data might be collected via multiple routes, and certain SDH data are already collected regularly by most CHCs. Thus, there was a need for an EHR-based summary that contains all of a patient's SDH data. We created an SDH data summary that 
is automatically populated with data from any of the SDH data entry options and from SDH-related data elsewhere in the EHR. The SDH Summary also shows any SDH-related International Classification of Diseases, Tenth Revisions (ICD-10), codes from the patient's problem list and any past $\mathrm{SDH}$ referrals if they were associated with an SDH-related ICD-10 code (see more on this in "Tracking Past Referrals," below). "Positive screens" for SDH needs are visually highlighted. The algorithm used to identify positive screens is shown in Table 4. This summary could be accessed in 2 ways:

- An SDH Summary tab can be accessed in an open Office Visit or Patient Outreach encounter. The most recent $\mathrm{SDH}$ data for the patient is displayed, and the date(s) of data collection and referral are shown (Figure 2).

- A view in the EHR's Synopsis window can be accessed in a closed chart or open encounter displays a patient's SDH questionnaire responses over time, both as text and graphically (Figure 3).

For technical reasons, it was not feasible to show problem list data or referrals in the Synopsis version of the SDH Summary. Thus, each summary had information that the other lacked; that is, 1 had past referral information but only the most recent $\mathrm{SDH}$ data for a given patient; the other did not have past referrals but did present patients' SDH history, rather than just their most recent SDH data.

\section{Identifying Referral Options}

The pilot CHCs already had lists of SDH-related local resources in binders or on shared drives. These were not updated systematically, but rather only when someone on the team received new information and thought to update the list. The options for how CHC teams could do this systematically, using EHR-based tools, are shown in Table 2. All of them would be accessed via a hyperlink on the SDH Summary.

The preference list option was selected for several reasons. Creating linkages to an external agency's website was cost-prohibitive and required organizational contracts; thus, the study clinics might learn to rely on something that would incur costs after the study. Furthermore, some searches on these websites yielded results that were not specific to a location but rather gave statewide or nationwide data. The wiki options were rejected because users would have to leave the EHR system to access them, and the study sites were concerned about how to ensure that these documents were updated. The preference lists, however, used the same EHR function that the CHCs used for other referrals; involved discrete data fields, creating trackable data; and built on the CHC teams' local knowledge. One concern about the preference lists was that they must be updated manually. However, the study $\mathrm{CHCs}$ currently designate a staff member to update other preference lists (eg, for ordering laboratory tests), and the same person could be responsible for updating the SDH lists.

We helped the study clinics create "starter" preference lists for the SDH areas they prioritized (Figure 4). The resources listed in each were populated with data from each clinic's current method for keeping such information, then augmented by Web searches and reviewed by staff. The lists include names and contact information of relevant services and agencies, and include information such as "women and children only" and hours of operation, when available.

\section{Ordering Referrals}

The SDH referrals preference lists can be used to make internal referrals (eg, to a community health worker), have clinic staff facilitate external referrals (eg, calling an agency to schedule an appointment for the patient), or share agency information with patients at the encounter or in the after-visit summary so patients can follow up on their own. To make these easier to use, we created a new referral priority option of "no follow-up needed," which, if selected, informed CHC staff that they were not required to follow up on SDH referrals as they would for others. We also created a new referral type-“community referral, nonmedical" - so that SDH referrals would be excluded from related care quality measures. Another consideration here is that only certain care team members are authorized to make referrals of any kind; thus, support staff may need to be trained and authorized to use these tools.

\section{Tracking Past Referrals}

As described above, the SDH Summary accessed through the Summary tab (Figure 3) is automat- 
Table 4. Algorithm for Identifying Positive Social Determinant of Health Screens

\begin{tabular}{ccc}
\hline & Response Options (from Hard-Copy Version or & Responses That Flags a \\
Questions* & Flowsheet) & Positive Screen
\end{tabular}

1. How do you learn best?

2. What is the highest level of school that you have finished?

3. How hard is it for you to pay for the very basics like food, housing, heating, medical care, and medications?

4a. In the past month, have you slept outside, in a shelter, or in a place not meant for sleeping?

4b. In the past month, have you had concerns about the conditions and quality of your housing?

5. In the past 12 months, how many times have you moved from one home to another?

6a. In the past 12 months, (I/we) worried whether (my/our) food would run out before (I/we) got money to buy more.

$6 \mathrm{~b}$. In the past 12 months, the food that (I/we) bought just didn't last, and (I/we) didn't have money to get more.

6c. In the past 12 months, (I/we) couldn't afford to eat balanced meals.

7. In the past 12 months, have you ever been physically or emotionally hurt or threatened by a spouse/ partner or someone else you know?

8a. On average, how many: Days per week do you engage in moderate to strenuous exercise (like walking fast, running, jogging, dancing, swimming, biking, or other activities that cause a light or heavy sweat)?

8 b. On average, how many minutes do you exercise at this level?

9. Are you married or living together with someone in a partnership?
Reading

None

Listening

Looking at pictures

Less than a high school diploma None

High school diploma/GED

More than high school

Not hard at all

Somewhat hard

Very hard

If you answered "Somewhat hard" or "Very hard," what is it hard to pay for?

Food, utilities, transportation, medicine or medical care, health insurance, clothing, rent/mortgage, child care, phone

Yes

No

Yes

No

(Patient to indicate number of times)

Often true

Sometimes true

Never true

Often true

Sometimes true

Never true

Often true

Sometimes true

Never true

Yes

No

Yes

Yes

$\geq 2$ moves flagged for follow-up

Often true or sometimes true

Often true or sometimes true

Often true or sometimes true

Yes

(Patient to choose a number between 0 and 7)

Multiply days per week (8a) by number of minutes (8b); $<150$ flagged for follow-up

(Patient to indicate number of minutes)

Married or domestic partner

Living with partner in committed relationship

In a serious or committed relationship, but not living together

Single

Separated

Divorced

Widowed
Questions 9-11:

Composite score based on the Berkman-Syme Social Network Index

Question 9: 1 point for "married or domestic partner," "living with partner in committed relations," or "in a serious or committed relationship, but not living together" 


\begin{tabular}{|c|c|c|}
\hline Questions* & $\begin{array}{c}\text { Response Options (from Hard-Copy Version or } \\
\text { Flowsheet) }\end{array}$ & $\begin{array}{l}\text { Responses That Flags a } \\
\text { Positive Screen }\end{array}$ \\
\hline $\begin{array}{l}\text { 10a. In a typical week, how often do } \\
\text { you: Talk with family, friends, or } \\
\text { neighbors by phone or video chat } \\
\text { (e.g. Skype, Facetime)? }\end{array}$ & $\begin{array}{l}\text { Never } \\
\text { Once a week } \\
\text { 2 Days a week } \\
\text { 3-5 Days a week } \\
\text { Nearly every day }\end{array}$ & $\begin{array}{l}\text { Question } 10 \mathrm{a}-\mathrm{c}: 1 \text { point if } \\
\text { they have a total of } \geq 3 \\
\text { contacts per week. }\end{array}$ \\
\hline $\begin{array}{l}\text { 10b. In a typical week, how often do } \\
\text { you get together with family, } \\
\text { friends, or neighbors? }\end{array}$ & $\begin{array}{l}\text { Never } \\
\text { Once a week } \\
2 \text { Days a week } \\
\text { 3-5 Days a week } \\
\text { Nearly every day }\end{array}$ & \\
\hline $\begin{array}{l}\text { 10c. In a typical week, how often do } \\
\text { you use email, text messaging, or } \\
\text { internet (eg, Facebook) to } \\
\text { communicate with family, friends, } \\
\text { or neighbors? }\end{array}$ & $\begin{array}{l}\text { Never } \\
\text { Once a week } \\
2 \text { Days a week } \\
\text { 3-5 Days a week } \\
\text { Nearly every day }\end{array}$ & \\
\hline $\begin{array}{l}\text { 11a. How often do you attend } \\
\text { church or religious services? }\end{array}$ & $\begin{array}{l}\text { Never } \\
\text { Once a year } \\
2-3 \text { Times a year } \\
\geq 4 \text { Times a year } \\
\text { At least once a month } \\
\text { At least once a week }\end{array}$ & $\begin{array}{l}\text { Question 11a: } 1 \text { point for } \\
\text { attending church or } \\
\text { attending church or } \\
\text { religious services " } \geq 4 \\
\text { times a year," "at least } \\
\text { once a month," or "at } \\
\text { least once a week" }\end{array}$ \\
\hline $\begin{array}{l}\text { 11b. Attend meetings of the clubs or } \\
\text { organizations you belong to? }\end{array}$ & $\begin{array}{l}\text { Never } \\
\text { Once a year } \\
2-3 \text { Times a year } \\
\geq 4 \text { Times a year } \\
\text { At least once a month } \\
\text { At least once a week }\end{array}$ & $\begin{array}{l}\text { Question } 11 \text { b: } 1 \text { point if } \\
\text { attends meetings " } 2-3 \\
\text { times a year," " } \geq 4 \\
\text { times a year," "at least } \\
\text { once a month," or "at } \\
\text { least once a week") } \\
\text { Maximum points }=4 \\
\text { High risk (flagged for } \\
\text { follow-up) }=0-2\end{array}$ \\
\hline $\begin{array}{l}\text { 12. How often do you feel lonely or } \\
\text { isolated from those around you? }\end{array}$ & $\begin{array}{l}\text { Never } \\
\text { Rarely } \\
\text { Sometimes } \\
\text { Often } \\
\text { Always }\end{array}$ & Often or always \\
\hline $\begin{array}{l}\text { 13. Do you have someone you could } \\
\text { call if you needed help? }\end{array}$ & $\begin{array}{l}\text { Yes } \\
\text { No }\end{array}$ & No \\
\hline $\begin{array}{l}\text { 14. During the past month, how } \\
\text { much stress would you say you } \\
\text { experienced? }\end{array}$ & $\begin{array}{l}\text { A lot of stress } \\
\text { A moderate amount of stress } \\
\text { Relatively little stress } \\
\text { Almost no stress at all }\end{array}$ & $\begin{array}{l}\text { A lot of stress or a } \\
\text { moderate amount of } \\
\text { stress }\end{array}$ \\
\hline
\end{tabular}

\footnotetext{
*Question sources: (1) Developed by OCHIN's Clinical Operations Review Committee. (2) Adapted from standard education questions to align with patient population of OCHIN membership. (3) Slight modification of Institute of Medicine-recommended financial hardship item (medications added to list of examples), Puterman et al, ${ }^{61}$ and Hall et al. ${ }^{62}$ The follow-up question, "What is hard to pay for?" was added to get more granularity and enable the care team to identify needed interventions; the question was adapted from a Kaiser Permanente social determinants of health (SDH) questionnaire, with permission. (4) and (5) Housing questions were from the Health Begins Upstream Risk Screening Tool (http://www.healthbegins.org/). ${ }^{63}$ (6) US Department of Agriculture 18-item Household Food Security Survey. (7) Adapted from a Kaiser Permanente SDH questionnaire, with permission. (8) Exercise Vital Sign, questions 1 and 2 and Sallis RE. Developing health care systems to support exercise: exercise as the fifth vital sign. $\mathrm{Br}$ 7 Sports Med 2011;45:473-4. Epic already has copyright permission. (9-11) Third National Health and Nutrition Examination Survey. Epic already has permission to use this question. Scoring is based on the Berkman-Syme Social Network Index (SNI); Pantell et al. Social isolation: a predictor of mortality comparable to traditional clinical risk factors. Am J Public Health 2013;103:2056-62. Item $10 \mathrm{c}$ was created as a parallel to items $10 \mathrm{a}$ and $10 \mathrm{~b}$ to capture social connection via newer electronic modes that were not available when the Berkman-Syme SNI was created. Frequency categories for questions 10 and 11 were slightly modified from original. Kaiser is also using this approach in their screening tool. Epic already has permission to use this question. (12) Modified from item in PROMIS Item Bank version 1.0, Emotional Distress - Anger - Short Form 1 - and AARP overall loneliness item from AARP survey about loneliness in older adults. The original PROMIS item was written in first person. Loneliness was added to reduce literacy level. (13) Your Current Life Situation Questionnaire from Kaiser Permanente. (14) 1998 Adult Prevention Module of the National Health Interview Survey.
} 
Figure 2. Social determinants of health summary tab.

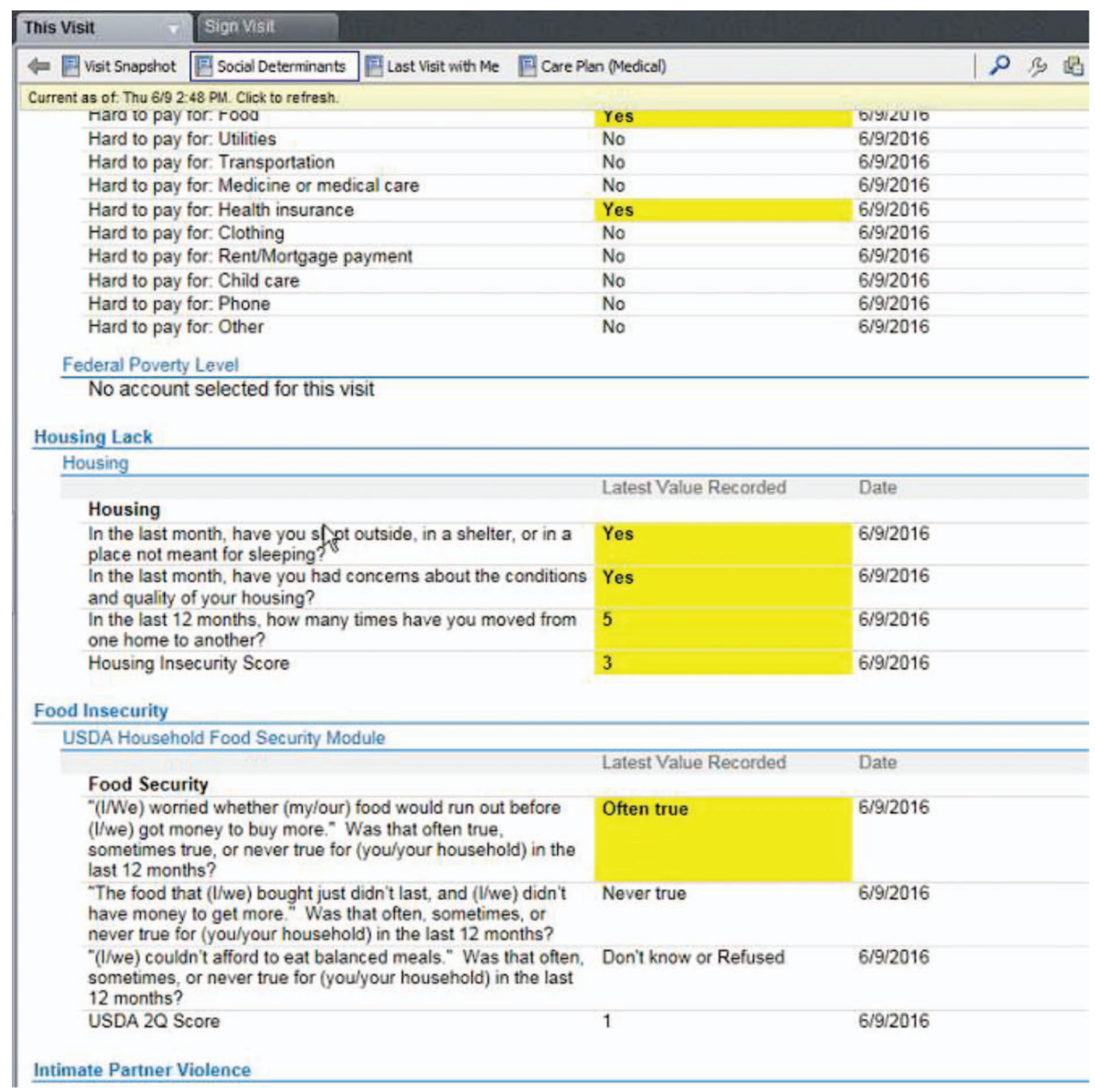

ically populated with information on past SDHrelated referrals in order to enable $\mathrm{CHC}$ teams to track them. Referrals are shown in the SDH Summary if they are tied to a relevant ICD-10 code and/or if the SDH referral preference list was used. Presented data include the date of referral, contact information about the community resource, status of the referral, and who ordered it. Care team members authorized to edit referrals can manually update the referral status.

\section{Lessons Learned}

Lessons learned here may inform future efforts to build EHR tools for collecting and acting on SDH data. Because these lessons come from a pilot study conducted in $3 \mathrm{CHCs}$, we present them for consideration, not as a set of directions for SDH data tool development.

Considerations for Which SDH Questions to Include Consider striking a balance between standardized $\mathrm{SDH}$ data collection (ie, aligned with the IOM- 
Figure 3. Social determinants of health summary in Synopsis.

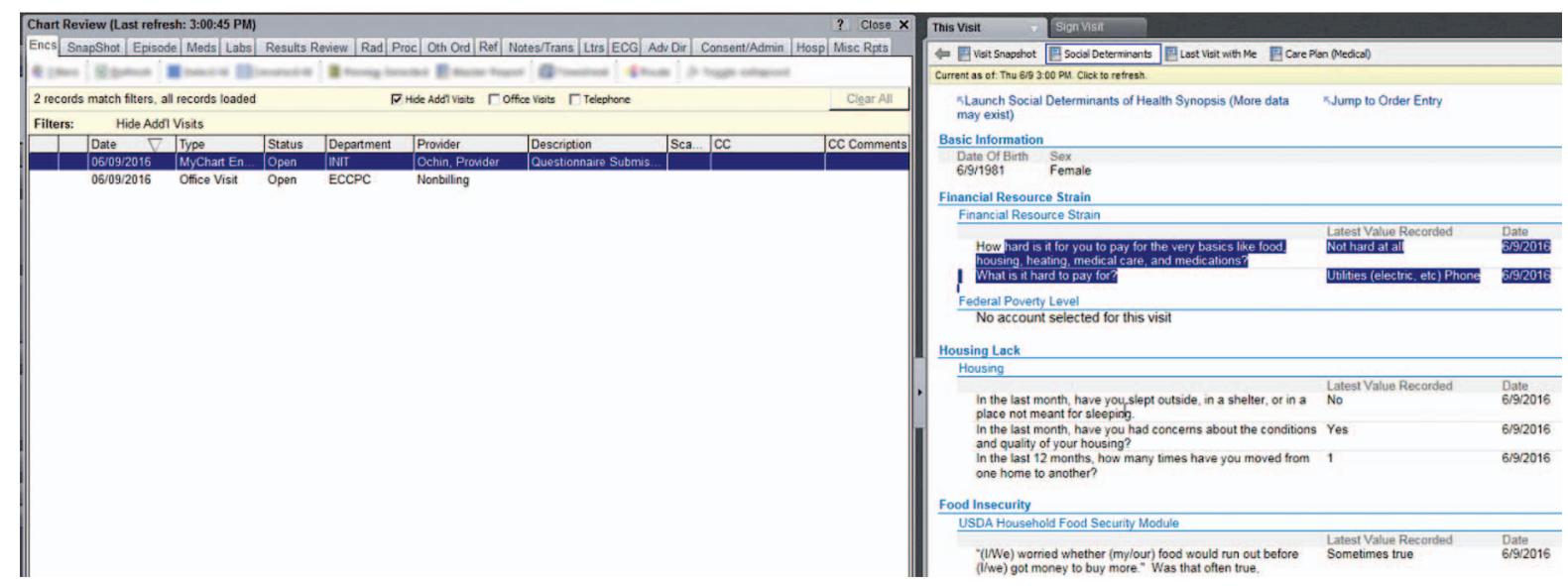

recommended measures) and the need to adapt to meet local needs, especially given that SDH data collection may become required for EHR certification and Uniform Data System reporting.

\section{Considerations for Designing SDH Data Collection Tools}

Patients may decline to answer SDH questions. Consider having SDH tools include a "patient refused to answer" option. Consider the advisability of including a "decline to answer" option on patient-facing data collection tools, which might make it too easy for patients to decline. Also, ensure that EHR-based SDH data tools do not require duplicate entry of SDH data collected elsewhere in workflows.

Patients with a positive SDH screening result may not want assistance in addressing the identified need. Consider creating EHR-based SDH data tools that include response options to indicate this preference, or to otherwise note that help was offered and declined.

Figure 4. Social determinants of health preference lists.

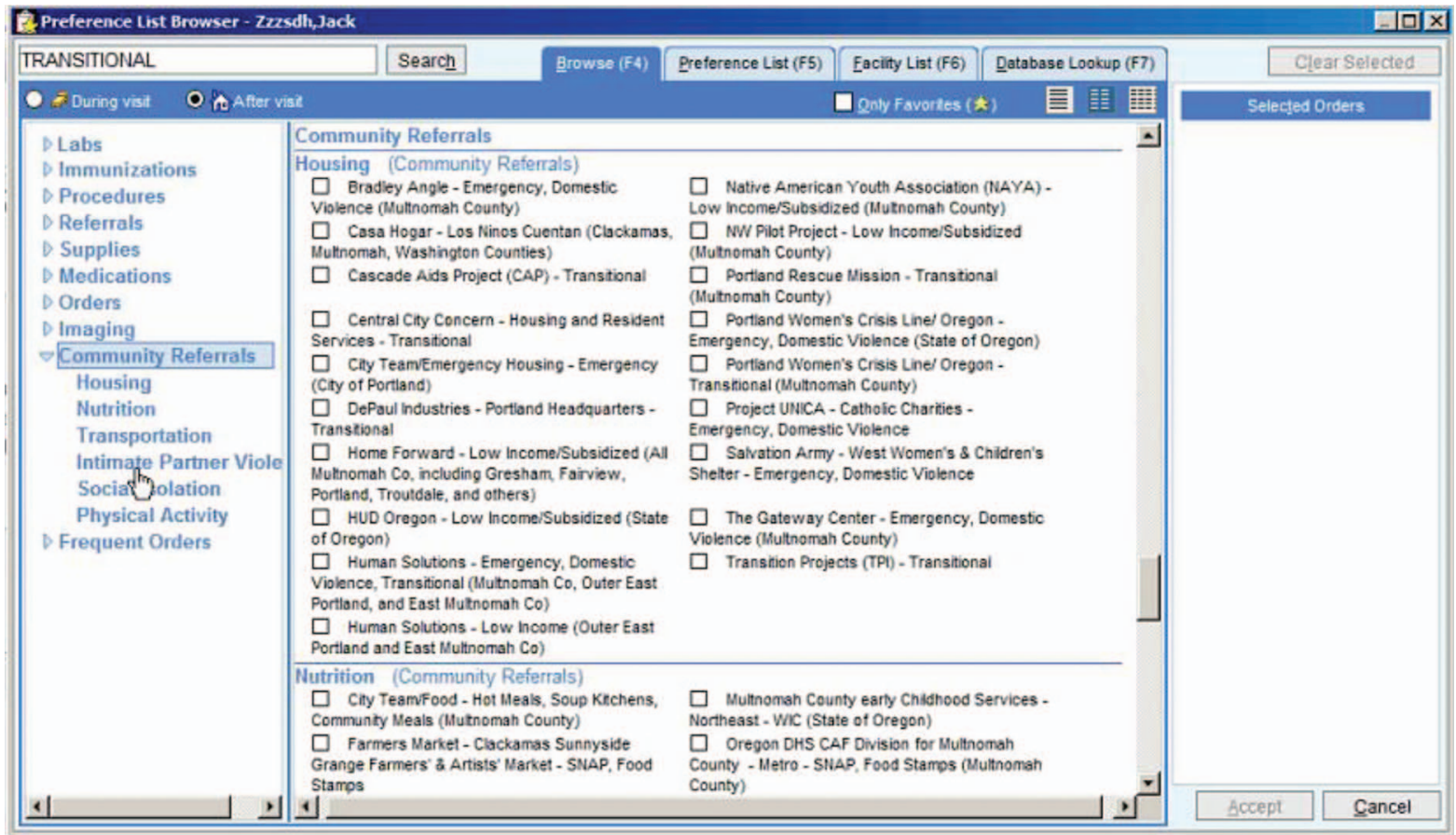


Considerations for Designing SDH Data Summary Tools

Carefully consider which SDH data sources should populate the SDH data summary and how to manage potentially conflicting data.

\section{Considerations for Designing SDH Referral Tracking Tools:}

Monitoring the outcomes of past SDH-related referrals is challenging, and often requires outreach calls to patients. Consider whether this ability is desired.

ICD-10 codes related to SDH needs enable the tracking of such needs, but they may add to the complexity of the problem list. Consider creating an SDH "box" within the problem list.

\section{Considerations for Maintaining Up-to-Date SDH Referral Tools:}

SDH referral tools rely on updated lists of local resources. Consider whether established processes for maintaining other referral lists can be applied to $\mathrm{SDH}$ tools. Consider partnering with organizations that maintain such lists.

\section{Considerations for SDH-Related Workflows}

EHR-based SDH data tools need to accommodate diverse staffing structures, resources, and workflows. Consider ensuring that the appropriate care team members are authorized to access all aspects of the tools.

To avoid overwhelming clinic staff and care teams with SDH-related work, consider limiting SDH screening to a subset of patients and ensuring that EHR-based SDH data tools enable targeting this subset. Consider creating an alert to identify overdue patients. To avoid overwhelming care teams, consider designing the EHR tools so that SDH-related referrals can be marked "no follow-up needed."

Consider using electronic tablets ${ }^{66-68}$ to enable SDH screening at registration or upon rooming, with workflows for using and tracking them. Clinics will need wireless Internet to enable tablets to transmit SDH data to the EHR.

To use patient portals for SDH data collection, consider developing workflows for helping patients create portal accounts at registration then enter their SDH data through the portal on the spot. Tablets may be useful here as well.

\section{Discussion}

Standardized SDH data collection and presentation using EHR tools could facilitate diverse pathways to improved patient and population health outcomes in CHCs and other care settings. It could provide important contextual information to care teams, facilitate referrals to local resources, inform clinical decision making, ${ }^{69}$ enable targeted outreach efforts, and support care coordination with community resources. $^{22,69,70}$ (We focused on how $\mathrm{SDH}$ data could be used to facilitate referring patients to local resources; research is needed on how else SDH data could inform clinical decisions). Such standardization will also provide data needed to document the SDH needs of CHC communities, inform policy and public health initiatives to improve health, and evaluate how addressing SDH risks affects health.

To attain these potential benefits, health care organizations need guidance on how to facilitate systematic SDH screening in primary care settings using EHR-based tools. ${ }^{43,71,72}$ Little such guidance currently exists; we know of no previously published reports on processes used to develop EHRbased SDH data collection, summary, and referral tools. This article presents an example of a process through which stakeholder input informed the development of a preliminary set of $\mathrm{SDH}$-focused EHR tools. While the results and lessons learned from our process may be useful to other organizations undertaking such efforts, they are preliminary and based on opinions from a relatively small group of stakeholders, health informaticists, and health services researchers. Extensive research is needed to empirically test the generalizability of these lessons.

The authors thank Edward Mossman, MPH (OCHIN, Inc); Marla Dearing (OCHIN, Inc); and Katie Dambrun, MPH, for their contributions toward this manuscript and overall ASSESS \& DO planning efforts. The authors also thank the staff at the pilot sites-Jennifer Hale, RN (Cowlitz Family Health Center); James Stoltz, RN (Cowlitz Family Health Center); and Maria Zambrano (La Clinica Health Center)—who provided feedback on clinic workflows and implementation efforts. The authors also thank collaborators Ranu Pandey, MHA (Kaiser Permanente Care Management Institute); Matthew C. Stiefel, MS, MPA (Kaiser Permanente Care Management Institute); and OCHIN's Clinical Operations Review Committee for their input on development of the SDH data collection tool. All EHR images used with permission. Copyright Epic 2017.

To see this article online, please go to: http://jabfm.org/content/ 30/4/428. full. 


\section{References}

1. Social determinants of health: what are social determinants of health? Geneva: World Health Organization; 2017. Available from: http://www.who.int/ social_determinants/sdh_definition/en/. Accessed October 3, 2016.

2. US Department of Health \& Human Services. Healthy People 2010, 2nd ed. Washington, DC: US Government Printing Office; 2000.

3. Smedley BD, Stith AY, Nelson AR, eds; Institute of Medicine Committee on Understanding and Eliminating Racial and Ethnic Disparities in Health Care. Unequal treatment: confronting racial and ethnic disparities in health care. Washington, DC: National Academies Press; 2005.

4. Stringhini S, Sabia S, Shipley M, et al. Association of socioeconomic position with health behaviors and mortality. JAMA 2010;303:1159-66.

5. Kann L, Olsen EO, McManus T, et al; Centers for Disease Control and Prevention (CDC). Sexual identity, sex of sexual contacts, and health-risk behaviors among students in grades 9-12-youth risk behavior surveillance, selected sites, United States, 2001-2009. MMWR Surveill Summ 2011;60:1-133.

6. Tarlov AR. Public policy frameworks for improving population health. Ann N Y Acad Sci 2006;896: 281-93.

7. Marmot MG, Shipley MJ. Do socioeconomic differences in mortality persist after retirement? 25 year follow up of civil servants from the first Whitehall study. BMJ 1996;313:1177-80.

8. Frieden TR. A framework for public health action: the health impact pyramid. Am J Public Health 2010; 100:590-5.

9. Fenton. Health care's blind side: the overlooked connection between social needs and good health. Princeton, NJ: Robert Wood Johnson Foundation; 2011. Available from: http://www.rwjf.org/en/ library/research/2011/12/health-care-s-blind-side. html. Accessed June 21, 2017.

10. Woolf SH, Johnson RE, Phillips RL Jr, Philipsen M. Giving everyone the health of the educated: an examination of whether social change would save more lives than medical advances. Am J Public Health 2007;97:679-83.

11. Chandola T, Ferrie J, Sacker A, Marmot M. Social inequalities in self reported health in early old age: follow-up of prospective cohort study. BMJ 2007; 334:990.

12. Galobardes B, Davey SG, Jeffreys M, McCarron P. Childhood socioeconomic circumstances predict specific causes of death in adulthood: the Glasgow student cohort study. J Epidemiol Community Health 2006;60:527-9.

13. Hammig O, Bauer GF. The social gradient in work and health: a cross-sectional study exploring the relationship between working conditions and health inequalities. BMC Public Health 2013;13:1170.
14. Krieger N, Kosheleva A, Waterman PD, Chen JT, Beckfield J, Kiang MV. 50-Year trends in US socioeconomic inequalities in health: US-born black and white Americans, 1959-2008. Int J Epidemiol 2014; 43:1294-313.

15. Lahiri S, Moure-Eraso R, Flum M, Tilly C, Karasek $\mathrm{R}$, Massawe E. Employment conditions as social determinants of health. Part I: the external domain. New Solut 2006;16:267-88.

16. Moure-Eraso R, Flum M, Lahiri S, Tilly C, Massawe E. A review of employment conditions as social determinants of health part II: the workplace. New Solut 2006;16:429-48.

17. Lahelma E, Laaksonen M, Aittomaki A. Occupational class inequalities in health across employment sectors: the contribution of working conditions. Int Arch Occup Environ Health 2009;82:185-90.

18. Ferrie JE, Shipley MJ, Davey SG, Stansfeld SA, Marmot MG. Change in health inequalities among British civil servants: the Whitehall II study. J Epidemiol Community Health 2002;56:922-6.

19. van Lenthe FJ, Borrell LN, Costa G, et al. Neighbourhood unemployment and all cause mortality: a comparison of six countries. J Epidemiol Community Health 2005;59:231-7.

20. Barnett E, Casper M. A definition of "social environment”. Am J Public Health 2001;91:465.

21. Kawachi I, Berkman LF. Neighborhoods and health. New York: Oxford University Press; 2003.

22. Institute of Medicine. Recommended social and behavioral domains and measures for electronic health records. Available from: http://nationalacademies.org/ hmd/Reports/2014/EHRdomains2.aspx Accessed June 2017. Published November 2014.

23. Adler NE, Stead WW. Patients in context-EHR capture of social and behavioral determinants of health. N Engl J Med 2015;372:698-701.

24. Office of the National Coordinator for Health Information Technology. The federal health IT strategic plan, 2015-2020. Available from: https:/www. healthit.gov/sites/default/files/9-5-federalhealth itstratplanfinal_0.pdf. Accessed October 2, 2016.

25. Committee on the Recommended Social and Behavioral Domains and Measures for Electronic Health Records, Board on Population Health and Public Health Practice, Institute of Medicine. Capturing social and behavioral domains and measures in electronic health records: phase 2. Washington, DC: National Academies Press; 2014.

26. Centers for Disease Control and Prevention. Meaningful use: CMS timeline of important MU dates. Available from: http://www.cdc.gov/ehrmeaningful use/timeline.html. Accessed October 9, 2016.

27. Tagalicod R, Reider J; Centers for Medicare \& Medicaid Services. Progress on adoption of electronic health records. Available from: https://www.cms. gov/eHealth/ListServ_Stage3 Implementation. 
html. Last modified December 13, 2013. Accessed September 12, 2016.

28. HealthIT.gov. HITPC meaningful use stage 3 final recommendations. Available from: https://www. healthit.gov/facas/sites/faca/files/HITPC_MUWG_ Stage3_Recs_2014-04-01.pdf. Accessed June 1, 2017.

29. MACRA: delivery system reform, Medicare payment reform. Baltimore: Centers for Medicare \& Medicaid Services; 2016. Available from: https://www.cms.gov/ Medicare/Quality-Initiatives-Patient-AssessmentInstruments/Value-Based-Programs/MACRAMIPS-and-APMs/MACRA-MIPS-and-APMs. html. Accessed September 9, 2016.

30. Bailey SR, O’Malley JP, Gold R, Heintzman J, Marino $M$, DeVoe JE. Receipt of diabetes preventive services differs by insurance status at visit. Am J Prev Med 2015;48:229-33.

31. Gold R, DeVoe JE, McIntire PJ, Puro JE, Chauvie SL, Shah AR. Receipt of diabetes preventive care among safety net patients associated with differing levels of insurance coverage. J Am Board Fam Med 2012;25:42-9.

32. Gold R, DeVoe J, Shah A, Chauvie S. Insurance continuity and receipt of diabetes preventive care in a network of federally qualified health centers. Med Care 2009;47:431-9.

33. Hsu CC, Lee CH, Wahlqvist ML, et al. Poverty increases type 2 diabetes incidence and inequality of care despite universal health coverage. Diabetes Care 2012;35:2286-92.

34. Lipton RB, Liao Y, Cao G, Cooper RS, McGee D. Determinants of incident non-insulin-dependent diabetes mellitus among blacks and whites in a national sample. The NHANES I epidemiologic follow-up study. Am J Epidemiol 1993;138:826-39.

35. Lysy Z, Booth GL, Shah BR, Austin PC, Luo J, Lipscombe LL. The impact of income on the incidence of diabetes: a population-based study. Diabetes Res Clin Pract 2013;99:372-9.

36. Jones-Smith JC, Karter AJ, Warton EM, et al. Obesity and the food environment: income and ethnicity differences among people with diabetes: the Diabetes Study of Northern California (DISTANCE). Diabetes Care 2013;36:2697-705.

37. Muennig P, Franks P, Jia H, Lubetkin E, Gold MR. The income-associated burden of disease in the United States. Soc Sci Med 2005;61:2018-26.

38. Li V, McBurnie MA, Simon M, et al. Impact of social determinants of health on patients with complex diabetes who are served by national safety-net health centers. J Am Board Fam Med 2016;29:356-70.

39. Frieden TR. Forward: CDC health disparities and inequalities report - United States, 2011. MMWR Surveill Summ 2011;60:1-2.

40. The Menges Group. Positively impacting social determinants of health: how safety net health plans lead the way. June 2014. Available from: http://www. communityplans.net/Portals/0/Fact\%20Sheets/
ACAP_Plans_and_Social_Determinants_of_Health. pdf. Accessed June 21, 2017.

41. Community health centers leveraging the social determinants of health. Alexandria, VA: Institute for Alternative Futures; 2012. Available from: http:// www.altfutures.org/pubs/leveragingSDH/IAFCHCsLeveragingSDH.pdf. Accessed June 1, 2017.

42. Bachrach D, Pfister H, Wallis K, Lipson M. Addressing patients' social needs: an emerging business case for provider investment. New York: Commonwealth Fund; 2014.

43. Garg A, Toy S, Tripodis Y, Silverstein M, Freeman E. Addressing social determinants of health at well child care visits: a cluster RCT. Pediatrics 2015;135: e296-304.

44. Chung EK, Siegel BS, Garg A, et al. Screening for social determinants of health among children and families living in poverty: a guide for clinicians. Curr Probl Pediatr Adolesc Health Care 2016;46:135-53.

45. Institute of Medicine. Capturing social and behavioral domains in electronic health records: phase 1 . Washington, DC: National Academies Press; 2014.

46. US Preventive Services Task Force. Grade definitions. June 2016. Available from: https://www. uspreventiveservicestaskforce.org/Page/Name/ grade-definitions. Accessed October 29, 2016.

47. Karsh BT. Beyond usability: designing effective technology implementation systems to promote patient safety. Qual Saf Health Care 2004;13:388-94.

48. Aoyama M. Beyond software factories: concurrentdevelopment process and an evolution of software process technology in Japan. Inf Softw Technol 1996;38:133-43.

49. Miller WL, Crabtree BF, McDaniel R, Stange $\mathrm{KC}$. Understanding change in primary care practice using complexity theory. J Fam Pract 1998;46: 369-76.

50. Rauterberg M, Strohm O. Work organization and software development. Ann Rev Autom Program 1992;16(Pt 2):121-8.

51. Rauterberg M, Strohm O. Benefits of user-oriented software development based on an iterative cyclic process model for simultaneous engineering. Int JInd Ergon 1995;16:391-410.

52. Boehm B, Egyed A. Optimizing software product integrity through life-cycle process integration. Comput Stand Interfaces 1999;21:63-75.

53. Cooper RG. Overhauling the new product process. J Consum Res 1996;25:482.

54. Gurses AP, Marsteller JA, Ozok AA, Xiao Y, Owens $\mathrm{S}$, Pronovost PJ. Using an interdisciplinary approach to identify factors that affect clinicians' compliance with evidence-based guidelines. Crit Care Med 2010;38:S282-S291.

55. Pronovost PJ, Goeschel CA, Marsteller JA, Sexton JB, Pham JC, Berenholtz SM. Framework for patient safety research and improvement. Circulation 2009; 119:330-7. 
56. Davis FD, Bagozzi RP, Warshaw PR. User acceptance of computer technology: a comparison of two theoretical models. Manage Sci 1989;35:9821003.

57. Davis FD. User acceptance of information technology: system characteristics, user perceptions and behavioral impacts. Int J Man Mach Stud 1993;38:475-87.

58. Venkatesh V. Determinants of perceived ease of use: integrating control, intrinsic motivation, and emotion into the technology acceptance model. Inform Syst Res 2000;11:342-65.

59. Sherin KM, Sinacore JM, Li XQ, Zitter RE, Shakil A. HITS: a short domestic violence screening tool for use in a family practice setting. Fam Med 1998; 30:508-12.

60. Shakil A, Bardwell J, Sherin K, Sinacore JM, Zitter R, Kindratt TB. Development of Verbal HITS for intimate partner violence screening in family medicine. Fam Med 2014;46:180-5.

61. Puterman E, Haritatos J, Adler NE, Sidney S, Schwartz JE, Epel ES. Indirect effect of financial strain on daily cortisol output through daily negative to positive affect index in the Coronary Artery Risk Development in Young Adults Study. Psychoneuroendocrinology 2013;38:2883-9.

62. Hall MH, Matthews KA, Kravitz HM, et al. Race and financial strain are independent correlates of sleep in midlife women: the SWAN sleep study. Sleep 2009;32:73-82.

63. Manchanda R, Gottlieb L. Upstream risks screening tool and guide version 2.6.. Los Angeles: HealthBegins; 2015.

64. Bureau of Primary Healthcare. 2016 Uniform Data System (UDS) reporting changes. April 12, 2016. Available from: http://bphc.hrsa.gov/datareporting/ reporting/2016udsreportingchanges.pdf. Accessed October 20, 2016.
65. Caiazza, T. Statement: new HHS rules require sexual orientation and gender identity data collection in electronic health records program. Center for American Progress, October 7,2015.Available from: https:// www.americanprogress.org/press/statement/2015/ 10/07/122884/statement-new-hhs-rules-requiresexual-orientation-and-gender-identity-datacollection-in-electronic-health-records-program/. Accessed October 20, 2016.

66. Harris SK, Knight JR. Putting the screen in screening: technology-based alcohol screening and brief interventions in medical settings. Alcohol Res 2014; 36:63-79.

67. Beadnall HN, Kuppanda KE, O'Connell A, Hardy TA, Reddel SW, Barnett MH. Tablet-based screening improves continence management in multiple sclerosis. Ann Clin Transl Neurol 2015; 2:679-87.

68. Anand V, McKee S, Dugan TM, Downs SM. Leveraging electronic tablets for general pediatric care: a pilot study. Appl Clin Inform 2015;6:1-15.

69. Gottlieb LM, Tirozzi KJ, Manchanda R, Burns AR, Sandel MT. Moving electronic medical records upstream: incorporating social determinants of health. Am J Prev Med. 2015;48:215-8.

70. Gottlieb L, Sandel M, Adler NE. Collecting and applying data on social determinants of health in health care settings. JAMA Intern Med 2013;173: 1017-20.

71. Garg A, Butz AM, Dworkin PH, Lewis RA, Thompson RE, Serwint JR. Improving the management of family psychosocial problems at low-income children's well-child care visits: the WE CARE Project. Pediatrics 2007;120:547-58.

72. Gottlieb L, Hessler D, Long D, Amaya A, Adler N. A randomized trial on screening for social determinants of health: the iScreen study. Pediatrics 2014; 134:e1611-8. 